\title{
Produção agroecológica de mudas e desenvolvimento a campo de couve-chinesa
}

\author{
Agroecological production of seedlings and field development of Chinese cabbage
}

\author{
Dinéia Tessaro $^{\mathrm{I}}$ Juliana Maria Matter $^{\mathrm{I}}$ Osvaldo Kuczman ${ }^{\mathrm{I}}$ Lucia de Fatima Furtado ${ }^{\mathrm{I}}$ \\ Luiz Antonio de Mendonça Costa ${ }^{\mathrm{I}}$ Monica Sarolli Silva de Mendonça Costa ${ }^{\mathrm{I}}$
}

RESUMO

O trabalho foi desenvolvido em duas etapas: a produção de mudas de couve-chinesa em bandejas e posterior transplante para o campo, objetivando avaliar o desempenho de diferentes substratos sobre o desenvolvimento da cultura. Para isso determinou-se, tanto na fase de formação das mudas, quanto nas plantas adultas, o comprimento da parte aérea, número de folhas, comprimento da raiz, massa seca da parte aérea, massa seca da raiz e diâmetro do coleto. A etapa de produção de mudas foi conduzida em ambiente protegido, com os seguintes tratamentos: $T_{0}$ substrato comercial Plantmax ${ }^{\circledR}(H A) ; T_{1}: 100 \%$ composto; $T_{2}: 95 \%$ composto $+2,5 \%$ areia $+2,5 \%$ pó de rocha; $T_{3}: 90 \%$ composto $+3 \%$ areia $+7 \%$ de pó de rocha e $T_{4}: 85 \%$ composto $+6 \%$ areia $+9 \%$ pó de rocha. Na produção de mudas, os substratos orgânicos, formulados com $100 \%$ e $85 \%$ composto, apresentaram melhores resultados, aos 15 e 28 DAS, respectivamente. Os resultados de campo demonstraram que adição de pó de rocha é um fator determinante no desempenho das mudas, sendo os melhores resultados obtidos nas parcelas cultivadas com mudas obtidas nos substratos formulados com 7 e $9 \%$ de pó de basalto.

Palavras-chave: Brassica pekinensis, pó de basalto, compostos orgânicos.

\section{ABSTRACT}

The research was carried out in two stages: the production of seedlings of chinese cabbage in trays with subsequent transplantation for the field, aiming to evaluate the performance of different substrates on the culture development. For this reason it was determined, both at the stage of formation of the seedlings, as in adult plants the length of the aerial part, number of leaves, root length, dry mass of the aerial part, root dry mass and diameter of the root collar. The experiment was conducted in a protected environment with the following treatments: $T_{0}$ Plantmax substrate ${ }^{\circledast}(H A) ; T_{I}: 100 \%$ compound; $T_{2}: 95 \%$ compost $+2.5 \%$ sand $+2.5 \%$ rock powder $; T_{3}: 90 \%$ compost $+3 \%$ sand $+7 \%$ powdered rock and $T_{4}: 85 \%$ compost $+6 \%$ sand $+9 \%$ rock powder. In the production of seedlings, the organic substrates formulated with $100 \%$ and $85 \%$ compound, had better results, the 15 and 28, respectively. The results of field have shown that the addition of rock powder is a determinant factor in the performance of seedlings, with the best results in the plots cultivated with seedlings obtained in the substrates formulated with 7 and $9 \%$ of basalt powder.

Key words: Brassica pekinensis, basalt powder, organic compounds.

\section{INTRODUÇÃO}

Na produção de oleráceas, o cultivo de brássicas tem grande importância na olericultura orgânica brasileira, devido ao grande volume de produção, ao retorno econômico e ao valor nutricional das espécies. As espécies mais cultivadas são repolho, couve-flor, couve-manteiga e brócolis, bem como a couve-chinesa (Brassica pekinensis) (FILGUEIRA, 2000; PERUCH et al., 2006), rica em vitaminas $\mathrm{A}, \mathrm{B}$ e C, cálcio, potássio e fibras, além da substância niacina, que reduz problemas no aparelho digestivo e sistema nervoso (MIKISHIMA, 1993).

A obtenção de mudas de qualidade é um importante fator no sucesso de implantação de hortas, influenciando diretamente no desempenho final das plantas nos canteiros de produção, tanto do ponto de vista nutricional quanto no ciclo produtivo

IDepartamento de Recursos Hídricos e Saneamento Ambiental, Universidade Estadual do Oeste do Paraná (UNIOESTE), Campus Cascavel, Rua Universitária, 2069, 85819-000, Cascavel, PR, Brasil. E-mail: ditessaro@ yhoo.com.br. *Autor para correspondência. 
da cultura (CARMELLO, 1995; GUIMARÃES et al., 2002; ECHER et al., 2007). Essa qualidade pode ser alcançada pelo uso de fertilizantes orgânicos de várias origens, destacando-se os compostos formulados a partir de estercos animais, que promovem melhorias nas características físicas, químicas e biológicas do solo, além de minimizar o uso de fertilizantes químicos (KIEHL, 1985). Adicionalmente, os adubos orgânicos servem como base para a formulação de substratos para produção de mudas, reduzindo os custos dessa atividade, especialmente se utilizados substratos regionais de fácil obtenção (MENEZES JUNIOR et al., 2000). Contudo, o uso de um único material dificilmente atenderá a todas as necessidades para a produção de mudas, sendo comum a combinação de dois ou mais materiais para obtenção de um substrato de qualidade que atenda todas as necessidades da planta (LIMA et al., 2009).

Considera-se como função primordial do substrato prover o suporte físico e nutricional das plantas. Por meio de sua fase sólida, o substrato influi na manutenção do sistema radicular da planta, suprimento de água e nutrientes, enquanto a fase líquida atua no suprimento de oxigênio e transporte de carbono entre as raízes e o ar externo pela fase gasosa, melhorando a relação água/ar e a disponibilidade de nutrientes. Além disso, os fatores $\mathrm{pH}$, capacidade de troca catiônica, salinidade e teor de matéria orgânica são as principais características químicas a serem consideradas (SCHMITZ et al., 2002).

Diante da importância e da escassez de informações sobre a couve-chinesa, bem como da necessidade de buscar métodos alternativos e econômicos na produção de hortaliças, objetivouse avaliar o desempenho de diferentes substratos na produção agroecológica e desenvolvimento a campo de mudas dessa planta.

\section{MATERIAL E MÉTODOS}

O experimento foi conduzido na área experimental da Universidade Estadual do Oeste do Paraná (UNIOESTE), em Cascavel- PR, com latitude de $02^{\circ} 46^{\prime} 483^{\prime \prime} \mathrm{S}$ e longitude de $72^{\circ} 39^{\prime} 117^{\prime \prime} \mathrm{W}$, e altitude média de 700m. O clima, segundo Köppen, é do tipo Cfa, com temperatura e precipitação média anual de $19,5^{\circ} \mathrm{C}$ e $1.950 \mathrm{~mm}$, respectivamente. $\mathrm{O}$ composto utilizado no experimento, tanto para as mudas como adubação dos canteiros, foi preparado com esterco bovino em confinamento, misturado com resíduos da máquina de pré-limpeza de cereais (milho, trigo e soja), os quais foram misturados e, semanalmente revolvidos e regados com água até a cura. Para a etapa de produção de mudas, foram utilizados cinco substratos, compondo cinco tratamentos, sendo eles, $\mathrm{T}_{0}$ - substrato comercial Plantmax $^{\circledast}(\mathrm{HA}) ; \mathrm{T}_{1}-100 \%$ composto (C); $\mathrm{T}_{2}$ $95 \% \mathrm{C}+2,5 \%$ areia (A) $(>0,18 \mathrm{~mm}$ e $<0,42 \mathrm{~mm})+$ $2,5 \%$ pó de basalto $(\mathrm{PB}) ; \mathrm{T}_{3}-90 \% \mathrm{C}+3 \% \mathrm{~A}+7 \%$ $\mathrm{PB} ; \mathrm{T}_{4}-85 \% \mathrm{C}+6 \% \mathrm{~A}+9 \% \mathrm{~PB}$, os quais foram caracterizados quimicamente, tabela 1.

Para o preparo dos substratos, o composto, areia e o pó de basalto foram previamente passados em peneira com malha 6 e $8 \mathrm{~mm}$, respectivamente, sendo então misturados nas porcentagens correspondentes aos tratamentos e homogeneizados. Em seguida, os substratos foram transferidos individualmente para cinco bandejas de poliestireno com 200 células. Cada bandeja corresponde a um bloco, o qual foi dividido em quatro parcelas, sendo cada parcela composta

Tabela 1 - Caracterização química dos substratos segundo sua porcentagem de composto $\left(\mathrm{T}_{0}\right.$ - substrato comercial Plantmax ${ }^{\mathbb{B}} ; \mathrm{T}_{1}-100 \%$ composto; $\mathrm{T}_{2}-95 \% \mathrm{C}+2,5 \%$ areia $(\mathrm{A})+2,5 \%$ pó de basalto (PB); $\mathrm{T}_{3}-90 \% \mathrm{C}+3 \% \mathrm{~A}+7 \% \mathrm{~PB} ; \mathrm{T}_{4}-85 \% \mathrm{C}+6 \% \mathrm{~A}+9 \% \mathrm{~PB}$ ).

\begin{tabular}{|c|c|c|c|c|c|}
\hline Parâmetros & Plantmax & $100 \%$ & $95 \%$ & $90 \%$ & $85 \%$ \\
\hline $\mathrm{P}\left(\mathrm{mg} \mathrm{dm}^{-3}\right)$ & 298,30 & 461,60 & 468,5 & 440,90 & 436,10 \\
\hline $\mathrm{C}\left(\mathrm{g} \mathrm{dm}^{-3}\right)$ & 64,68 & 63,90 & 63,90 & 51,82 & 50,26 \\
\hline $\mathrm{pH}$ & 5,10 & 6,00 & 6,00 & 6,00 & 5,90 \\
\hline $\mathrm{Ca}\left(\mathrm{cmol} \mathrm{dm}^{-3}\right)$ & 15,27 & 15,10 & 15,09 & 14,10 & 13,10 \\
\hline $\operatorname{Mg}\left(\mathrm{cmol} \mathrm{dm}{ }^{-3}\right)$ & 6,28 & 14,70 & 14,60 & 13,80 & 13,00 \\
\hline $\mathrm{K}\left(\mathrm{cmol} \mathrm{dm}{ }^{-3}\right)$ & 0,22 & 1,14 & 1,14 & 1,14 & 1,14 \\
\hline $\mathrm{Cu}\left(\mathrm{mg} \mathrm{dm}^{-3}\right)$ & 1,60 & 1,00 & 1,00 & 1,00 & 1,00 \\
\hline $\mathrm{Zn}\left(\mathrm{mg} \mathrm{dm}^{-3}\right)$ & 5,20 & 40,00 & 40,00 & 40,00 & 40,00 \\
\hline $\mathrm{Fe}\left(\mathrm{mg} \mathrm{dm}^{-3}\right)$ & 341,00 & 163,00 & 168,00 & 161,00 & 130,00 \\
\hline $\operatorname{Mn}\left(\mathrm{mg} \mathrm{dm}^{-3}\right)$ & 42,00 & 191,00 & 175,00 & 183,00 & 198,00 \\
\hline Capacidade de retenção de água (CRA) \% & 119,49 & 204,2 & 186,21 & 165,53 & 134,53 \\
\hline
\end{tabular}


por 50 células, perfazendo um total de 200 plantas por tratamento. Esse procedimento foi realizado para cada um dos substratos testados, resultando em cinco blocos inteiramente cazualizados com 200 plantas em cada, totalizando 1000 plantas. A semeadura da couve chinesa cv. 'Granat' foi manual com uma semente por cavidade e a irrigação realizada com regador, diariamente, pela manhã e à tarde.

Transcorridos 15 e 28 dias após semeadura (DAS), foram selecionadas aleatoriamente três plantas de cada parcela, totalizando 12 plantas por tratamento em cada um dos cinco blocos, perfazendo um total de 60 plantas em cada uma das coletas, sendo analisados os seguintes parâmetros fitométricos: Comprimento de Raiz (CR), Comprimento da Parte Aérea (CPA), Número de Folhas (NF), Massa Seca de Raiz (MSR), Massa Seca da Parte Aérea (MSPA) e Diâmetro do Coleto (DC). Para a realização das avaliações, as plantas foram retiradas das bandejas, lavadas para remoção do substrato aderido à raiz e secas ao ambiente.

As determinações dos parâmetros comprimento de raiz e comprimento da parte aérea foram realizadas com auxílio de régua graduada em milímetros, enquanto que o diâmetro do coleto foi determinado com paquímetro digital. Para a determinação da massa seca da parte aérea e massa seca de raiz, após mensuração dos demais parâmetros, as plantas foram separadas em parte aérea e raiz, acondicionadas individualmente em sacos de papel, secas em estufa de circulação de ar a $60^{\circ} \mathrm{C}$ até peso constante, com posterior pesagem em balança de precisão.

Após realizadas as análises fitométricas, aos 28DAS, procedeu-se ao transplante em canteiros previamente preparados, nas dimensões de $20 \mathrm{~m}$ de comprimento $\mathrm{x} 80 \mathrm{~cm}$ de largura, com sistema de irrigação por gotejamento. Antes do transplantio das mudas, procedeu-se à aplicação a lanço de $1,5 \mathrm{~kg} \mathrm{~m}^{-2}$ de adubo orgânico, constituído por $50 \%$ composto (C) (esterco de bovino em confinamento e resíduos da máquina de pré-limpeza de cereais) $+25 \%$ de pó de basalto (PB) e $25 \%$ de cinzas em todos os canteiros. $\mathrm{O}$ delineamento experimental utilizado foi em blocos casualizados contendo cinco tratamentos e quatro repetições, totalizando 20 parcelas. Cada parcela foi de 1,0 metro de comprimento por $80 \mathrm{~cm}$ de largura.

Para o transplante, foram selecionadas aleatoriamente nove plantas de cada tratamento, as quais foram transplantadas em cada parcela com espaçamento de $33 \mathrm{~cm}$ entre plantas e $26 \mathrm{~cm}$ entre linhas, totalizando nove plantas por parcela. Os tratamentos foram dispostos ao acaso nas parcelas na seguinte sequência: Bloco $1\left(\mathrm{~T}_{1}, \mathrm{~T}_{3}, \mathrm{~T}_{4}, \mathrm{~T}_{0}, \mathrm{~T}_{2}\right)$, Bloco
$2\left(\mathrm{~T}_{3}, \mathrm{~T}_{4}, \mathrm{~T}_{1}, \mathrm{~T}_{0}, \mathrm{~T}_{2}\right)$, Bloco $3\left(\mathrm{~T}_{4}, \mathrm{~T}_{3}, \mathrm{~T}_{2}, \mathrm{~T}_{0}, \mathrm{~T}_{1}\right) \mathrm{e}$ Bloco $4\left(\mathrm{~T}_{0}, \mathrm{~T}_{3}, \mathrm{~T}_{2}, \mathrm{~T}_{4}, \mathrm{~T}_{1}\right)$.

Transcorridos 76 dias do transplantio, foram escolhidas aleatoriamente 3 plantas por tratamento em cada uma das parcelas, totalizando 12 plantas por tratamento, as quais foram submetidas aos mesmos procedimentos e análises fitométricas utilizadas na fase de formação de mudas.

Os resultados obtidos nas duas etapas foram analisados estatisticamente, utilizando o Software livre Sisvar versão 4.3, segundo delineamento em blocos inteiramente casualizados com 4 repetições, sendo as médias analisadas pelo teste LSD a 5\% de probabilidade.

\section{RESULTADOS E DISCUSSÃO}

Na tabela 2, são apresentados os resultados obtidos aos 15 e 28DAS quanto aos parâmetros fitométricos comprimento da parte aérea (CPA), massa seca da parte aérea (MSPA), comprimento da raiz (CR), massa seca da raiz (MSR) e diâmetro do coleto (DC), para plantas de couve-chinesa.

A análise realizada aos 15DAS demonstra que ocorreram diferenças estatísticas significativas para todos os parâmetros fitométricos em virtude dos substratos avaliados. Em linhas gerais, observa-se que os melhores resultados foram obtidos pelos substratos alternativos em detrimento do substrato comercial Plantmax $^{\circledast}$. Tais resultados corroboram os obtidos por VITTI et al. (2007), os quais testaram diferentes substratos alternativos para a produção de mudas de alface e concluíram que o uso de substrato composto por dejeto bovino apresentou resultados superiores de comprimento de parte aérea, comprimento de raiz e diâmetro do coleto, quando comparados ao substrato comercial Plantmax ${ }^{\circledR}$. Segundo TRANI et al. (2004), os substratos disponíveis no mercado são recomendados indistintamente para grande número de culturas, sem considerar as características e necessidades nutricionais na fase da formação de mudas de cada hortaliça, atendidas com maior eficiência pelos substratos preparados com vários constituintes orgânicos e inorgânicos. Além disso, observa-se, na tabela 1, que os substratos alternativos apresentam, em linhas gerais, maior concentração de nutrientes, favorecendo melhores condições para o desenvolvimento inicial, chamando atenção para a concentração de zinco.

O zinco é considerado um elemento de grande importância para as plantas, participando como componente de um grande número de enzimas, no metabolismo de carboidratos, proteínas e 
Tabela 2 - Valores médios do comprimento da parte aérea (CPA), massa seca da parte aérea (MSPA), comprimento de raiz (CR), massa seca da raiz (MSR), número de folhas (NF) e diâmetro do coleto (DC), obtidos aos 15, 28 e 76 dias após semeadura da couve-chinesa.

\begin{tabular}{|c|c|c|c|c|c|c|}
\hline \multirow{2}{*}{ Tratamentos } & \multicolumn{6}{|c|}{ - } \\
\hline & $\mathrm{CPA}(\mathrm{cm})$ & $\operatorname{MSPA}(\mathrm{g})$ & $\mathrm{CR}(\mathrm{cm})$ & $\operatorname{MSR}(\mathrm{cm})$ & NF & $\mathrm{DC}(\mathrm{mm})$ \\
\hline $\mathrm{T}_{0}$ Plantmax & $6,36 \mathrm{~b}$ & $0,0301 \mathrm{c}$ & $9,06 \mathrm{ab}$ & $0,0063 \mathrm{~b}$ & $4,00 \mathrm{~b}$ & $1,05 \mathrm{c}$ \\
\hline $\mathrm{T}_{1}-100 \%$ & $10,52 \mathrm{a}$ & $0,0717 \mathrm{a}$ & $9,21 \mathrm{a}$ & $0,0210 \mathrm{a}$ & $4,75 \mathrm{a}$ & $1,60 \mathrm{a}$ \\
\hline $\mathrm{T}_{2}-95 \%$ & $10,20 \mathrm{a}$ & $0,0519 \mathrm{~b}$ & $7,55 \mathrm{bc}$ & $0,0094 \mathrm{~b}$ & $4,08 \mathrm{~b}$ & $1,53 \mathrm{ab}$ \\
\hline $\mathrm{T}_{3}-90 \%$ & 10,64 a & $0,0607 \mathrm{ab}$ & $8,42 a b c$ & $0,0095 \mathrm{~b}$ & $4,75 \mathrm{a}$ & $1,38 \mathrm{~b}$ \\
\hline $\mathrm{T}_{4}-85 \%$ & $11,05 \mathrm{a}$ & $0,0635 \mathrm{ab}$ & $7,15 \mathrm{c}$ & $0,0062 \mathrm{~b}$ & $4,66 \mathrm{a}$ & $1,54 \mathrm{ab}$ \\
\hline $\mathrm{T}_{0}$ - Plantmax & $9,83 \mathrm{c}$ & $0,0722 \mathrm{c}$ & $7,62 \mathrm{c}$ & $0,0142 \mathrm{~b}$ & $3,41 \mathrm{a}$ & $1,38 \mathrm{c}$ \\
\hline $\mathrm{T}_{1}-100 \%$ & $16,33 a b$ & $0,1516 \mathrm{~b}$ & $9,79 a b$ & $0,0238 \mathrm{ab}$ & $3,41 \mathrm{a}$ & $1,93 \mathrm{ab}$ \\
\hline $\mathrm{T}_{2}-95 \%$ & 17,07 a & $0,2218 \mathrm{a}$ & $8,70 a b$ & $0,0253 \mathrm{ab}$ & $3,91 \mathrm{a}$ & $2,05 \mathrm{ab}$ \\
\hline $\mathrm{T}_{3}-90 \%$ & $16,17 a b$ & $0,1409 \mathrm{~b}$ & $9,86 \mathrm{a}$ & $0,0325 \mathrm{a}$ & $3,91 \mathrm{a}$ & $1,90 \mathrm{~b}$ \\
\hline $\mathrm{T}_{4}-85 \%$ & $1,14 a b$ & $0,1799 \mathrm{ab}$ & $8,44 a b$ & $0,0403 \mathrm{a}$ & $3,66 a$ & $2,23 \mathrm{a}$ \\
\hline $\mathrm{T}_{0}$ - Plantmax & 53,59 a & $37,01 \mathrm{~b}$ & $20,30 \mathrm{a}$ & $3,48 \mathrm{a}$ & $33,33 \mathrm{~b}$ & $23,15 \mathrm{ab}$ \\
\hline $\mathrm{T}_{1}-100 \%$ & $46,75 \mathrm{a}$ & $22,30 \mathrm{~b}$ & 10,05 a & $2,70 \mathrm{a}$ & $30,83 \mathrm{~b}$ & $16,22 \mathrm{~b}$ \\
\hline $\mathrm{T}_{2}-95 \%$ & 53,08 a & $36,74 \mathrm{~b}$ & 19,33 a & $3,44 \mathrm{a}$ & $33,16 \mathrm{~b}$ & $20,16 a b$ \\
\hline $\mathrm{T}_{3}-90 \%$ & 52,08 a & $39,53 \mathrm{a}$ & $20,97 \mathrm{a}$ & $3,98 \mathrm{a}$ & $52,16 \mathrm{a}$ & $25,09 \mathrm{a}$ \\
\hline $\mathrm{T}_{4}-85 \%$ & $50,00 \mathrm{a}$ & 39,29 a & $22,06 \mathrm{a}$ & $3,86 \mathbf{a}$ & $39,70 \mathrm{ab}$ & $22,00 \mathrm{ab}$ \\
\hline
\end{tabular}

Letras minúsculas na coluna não diferem entre si pelo teste LSD em nível de 5\% de significância.

fosfatos, além da formação da estrutura das auxinas, metabolismo dos fenóis e aumento do tamanho e multiplicação celular (BORKERT, 1989; TAIZ et al., 2004). O efeito benéfico do zinco também foi observado por RESENDE et al. (2008), por meio da suplementação do elemento em diferentes doses na produção de alface do tipo americana.

Observa-se ainda, pelas análises químicas dos compostos (Tabela 1), que os substratos alternativos apresentaram teores de fósforo muito superiores ao substrato comercial, o que justifica o padrão de desenvolvimento das mudas, pois o fósforo está relacionado ao papel de síntese de proteínas, por constituir nucleoproteínas necessárias à divisão celular (MALAVOLTA, 2006). Assim, o fósforo favorece o desenvolvimento radicular das hortaliças, aumentando a absorção de água e de nutrientes, o que pode promover melhorias na qualidade e rendimento dos produtos colhidos (AVALHAES, 2009). Observa-se ainda, nos substratos alternativos, maior concentração de magnésio, o qual, na planta, entre outras funções, faz parte da biossíntese da clorofila (MALAVOLTA, 1989). Adicionalmente, observa-se a maior capacidade de retenção de água nos substratos orgânicos, garantindo suporte hídrico adequado, o que contribui para o melhor desenvolvimento das mudas.
Embora as maiores médias tenham sido registradas, em linhas gerais, para os substratos alternativos, observam-se diferenças estatísticas entre esses tratamentos, exceto para o comprimento da parte aérea (CPA), em que todos apresentaram o mesmo potencial em suprir a planta adequadamente para o desenvolvimento em extensão de sua porção aérea. Dentre os demais parâmetros, o tratamento $\mathrm{T}_{1}$ (100\% de composto) destaca-se dos demais substratos alternativos, apresentando as maiores médias, embora não tenham ocorrido diferenças estatísticas em relação aos demais tratamentos em alguns dos parâmetros avaliados. Resultados semelhantes foram descritos por MENEZES JUNIOR \& FERNANDES (1998), os quais observaram que as utilizações de substratos formulados com maiores concentrações de compostos oriundos da bovinocultura eram mais viáveis na produção de mudas de couve-flor, devido a uma melhor combinação entre as propriedades químicas e físicas.

Os resultados demonstram que existe uma relação direta entre os parâmetros descritos, quando avaliados em $\mathrm{T}_{1}$ (100\% composto), ou seja, os maiores valores de número de folhas e comprimento de raiz refletiram diretamente sobre a massa seca da parte aérea, diâmetro do coleto e massa seca da raiz, que 
apresentaram os melhores resultados. Tal constatação demonstra que a couve-chinesa adapta-se de maneira bastante satisfatória ao substrato orgânico testado, com melhorias nas variáveis analisadas, podendo representar diminuição nos custos de produção de mudas. Além disso, o bom desenvolvimento da porção aérea, especialmente do número de folhas e o comprimento da raiz, são os parâmetros mais importantes no cultivo de mudas, pois são responsáveis pela fotossíntese e absorção de nutrientes.

Aos 28DAS, verifica-se, a exemplo da primeira análise, que a adoção de substratos orgânicos favoreceu o melhor desenvolvimento da couve chinesa, exceto para o número de folhas, não se observando diferenças significativas em nenhum dos substratos testados. Em relação à primeira coleta, houve redução do número de folhas, especialmente em $\mathrm{T}_{1}(100 \%$ composto). Tal resultado está, provavelmente, associado ao desenvolvimento acelerado da cultura nos substratos orgânicos, o que é confirmado pelo incremento dos valores dos demais parâmetros aos 28DAS. Sendo assim, acredita-se que o espaço disponível nas bandejas foi insuficiente para o crescimento adequado das mudas, bem como o sombreamento provocado pelo desenvolvimento das folhas superiores, levando à senescência das folhas emitidas inicialmente. Resultados semelhantes foram descritos por GODOY \& CARDOSO (2005), os quais verificaram número reduzido de folhas da couve-flor quando cultivadas em bandejas com 288 células se comparados às de 128 células.

Por outro lado, analisando os dados referentes ao comprimento da parte aérea, observase que o tratamento $\mathrm{T}_{2}$ (95\% composto) obteve os melhores resultados, embora não tenha diferido estatisticamente dos tratamentos $\mathrm{T}_{4}, \mathrm{~T}_{3} \mathrm{eT}_{1}(85 \%, 90 \%$ e $100 \%$ composto, respectivamente), contrapondose ao resultado obtido aos 15DAS, em que T1 (100\% composto) apresentou as maiores médias. Isso provavelmente ocorreu devido às propriedades físicas e químicas do composto, aliadas ao maior fornecimento de nutrientes oriundos do pó de rocha nos tratamentos $\mathrm{T}_{2}, \mathrm{~T}_{3}$ e $\mathrm{T}_{4}(95 \%, 90 \%$ e $85 \%$ composto, respectivamente). Segundo AMPARO (2003), a mineralização e liberação dos íons presentes no pó de rocha é lenta e gradativa, não estando disponíveis na fase inicial, justificando os diferentes resultados obtidos aos 15 e 28DAS. Tal explicação também pode ser aplicada ao parâmetro diâmetro do coleto (DC), em que o $\mathrm{T}_{4}(85 \%$ composto) apresentou o melhor resultado. Segundo RESENDE et al. (1997), a adição do pó de rocha, especialmente o proveniente de rochas vulcânicas, como o basalto, propicia a obtenção de um substrato com maior fertilidade, pois as rochas desse tipo são ricas em macro e micro nutrientes.

Quanto ao parâmetro comprimento de raiz, a maior média foi obtida pelo tratamento $\mathrm{T}_{3}$ (90\% composto), embora não tenha diferido estatisticamente dos tratamentos $\mathrm{T}_{1}, \mathrm{~T}_{2}$ e $\mathrm{T}_{4}(100 \%$, $95 \%$ e $85 \%$ de composto, respectivamente). Esses resultados encontram relação direta com os resultados obtidos para a massa seca de raiz, tendo em vista que esses tratamentos apresentaram as maiores médias, com destaque para o tratamento $\mathrm{T}_{4}$ ( $85 \%$ composto). Tal resultado provavelmente encontre-se associado à maior quantidade de pó de rocha neste tratamento, o que garantiu maior aporte de nutrientes nesta fase, não havendo a necessidade do crescimento em extensão das raízes pela busca de nutrientes, possibilitando a formação de raízes mais ramificadas e abundantes, aumentando a superfície de absorção, o que explica, de certa forma, a maior massa de raízes.

Na tabela 2, são apresentados os resultados dos parâmetros fitométricos obtidos aos 76 dias após o transplante das mudas. Observa-se que não ocorreram diferenças significativas quanto aos parâmetros comprimento da parte aérea, comprimento de raiz e massa seca de raiz em nenhum dos tratamentos testados.

Por outro lado, quanto à massa seca da parte aérea, observam-se diferenças significativas entre os tratamentos, sendo as maiores médias relativas aos tratamentos $\mathrm{T}_{3}$ e $\mathrm{T}_{4}(90 \%$ e $85 \%$ composto, respectivamente), os quais não diferiram entre si, contrapondo-se aos resultados obtidos aos 28DAS, em que melhores resultados foram obtidos para o tratamento $\mathrm{T}_{2}(95 \%$ composto). Tal constatação leva a crer que a maior quantidade de pó de rocha contida nesses tratamentos, na produção das mudas, possibilitou maior disponibilidade de nutrientes por maior período, pelo substrato ter aderido às raízes no ato do transplante, se comparado aos tratamentos que receberam menores proporções, bem como a maior capacidade de retenção de água. Além disso, segundo FILGUEIRA (2000), um bom enraizamento e reinício do desenvolvimento da planta após o choque do processo de transplante-o, são favorecidos por tecidos ricos em massa seca, como demonstrado aos 28DAS para os tratamentos $\mathrm{T}_{3}$ e $\mathrm{T}_{4}(90 \%$ e $85 \%$ composto, respectivamente), os quais apresentaram os maiores teores de massa seca de raiz. Tal resultado encontra uma relação direta com o número de folhas, maior também nesses tratamentos, o que lhes conferem maior massa seca da parte aérea, pois há maior área para a produção de fotoassimilados. Além disso, os parâmetros massa seca de parte aérea e número de folhas são especialmente importantes, 
pois, em hortaliças folhosas, essas características são responsáveis pelo volume e peso da parte aérea, determinantes para a comercialização (REGHIN et al., 2007).

Dentre os resultados obtidos, chama atenção os valores do $T_{1}$ (100\% composto), os menores dentre os testados para todos os parâmetros avaliados, contrapondo-se ao encontrado na produção de mudas, especialmente aos 15DAS, o qual forneceu as melhores condições. Tal resultado deixa claro que as plantas apresentam diferentes necessidades ao longo de seu desenvolvimento e, quando estes não são atendidos satisfatoriamente, ocorrem oscilações no padrão de desenvolvimento entre os tratamentos, como observado na produção de mudas e no transplante para os canteiros. Tais resultados podem estar associados a um possível stress das mudas neste tratamento, ocasionado por nutrientes. Essa suposição encontra suporte se observado que alguns dos parâmetros avaliados sofreram decréscimo aos 28DAS, em relação à análise realizada aos 15DAS, data em que o tratamento destaca-se quase que na totalidade dos parâmetros avaliados. Além disso, perante tal desenvolvimento, visivelmente superior aos demais tratamentos, a espera para o transplante de mudas aos 28DAS, pode ter sido outro fator agravante, pois as plantas podem ter feito uso dos nutrientes remanescentes para a manutenção de sua estrutura ao invés de desenvolvê-la. Esta hipótese, segundo ANDRIOLO et al. (2003), é possível, pois os autores verificaram, em seu estudo na produção de mudas de alface, que existe um período ótimo para o transplante, sendo que tal procedimento realizado de maneira prematura ou retardada influencia de maneira negativa no desenvolvimento das plantas em diferentes níveis.

\section{CONCLUSÃO}

De acordo com os parâmetros analisados neste experimento, pode-se afirmar que os substratos alternativos apresentaram resultados superiores ao substrato comercial, tanto na produção de mudas quanto na produção a campo de couve chinesa.

Considerando as vantagens observadas dos substratos alternativos, conclui-se que o substrato T3 $(90 \% \mathrm{C}+3 \% \mathrm{~A}+7 \% \mathrm{~PB})$ garante as melhores condições para a produção de mudas e desenvolvimento a campo de couve-chinesa.

\section{REFERÊNCIAS}

ANDRIOLO, J.L. et al. Crescimento e desenvolvimento de plantas de alface provenientes de mudas com diferentes idades fisiológica. Ciência Rural, v.33, n.1, p.35-40, 2003. Disponível em: <http://www.scielo.br/scielo.php?pid=S0103$84782003000100006 \&$ script $=$ sci_arttext $>$. Acesso em: 25 jan. 2011. doi: 10.1590/S0103-84782003000100006.

AMPARO, A. Farinha de rocha e biomassa. Agroecologia Hoje, n.20, p.10-12, 2003.

AVALHAES, C.C. et al. Rendimento e crescimento da beterraba em função da adubação com fósforo. Scientia Agraria, v.10, n.1, p.75-80, 2009. Disponível em: <http://redalyc.uaemex.mx/ redalyc/pdf/995/99515507011.pdf>. Acesso em: 29 jan. 2011.

BORKERT, C.M. Micronutrientes na planta. In: BÜLL, L.T.; ROSOLEM, C.A. Interpretação de análise química de solo e planta para fins de adubação. Botucatu: Fundação de Estudos e Pesquisas Agrícolas e Florestais, 1989. Cap.16, p.309-329.

CARMELLO, Q.A.C. Nutrição e adubação de mudas hortícolas. In: MINAMI, K. Produção de mudas de alta qualidade em horticultura. São Paulo: T.A. QUEIROZ, 1995. Cap.5, p.27-37.

ECHER, M.M. et al. Avaliação de mudas de beterraba em função do substrato e do tipo de bandeja. Semina: Ciências Agrárias, v.28, n.1, p.45-50, 2007. Disponível em: <http://www.uel.br/ revistas/uel/index.php/semagrarias/article/viewFile/2547/2196>. Acesso em: 29 jan. 2011.

FILGUEIRA, F.A.R. Novo manual de olericultura: agrotecnologia moderna na produção e comercialização de hortaliças. Viçosa: UFV, 2000. p.282.

GODOY, M.C.; CARDOSO, A.I.I. Produtividade da couveflor em função da idade de transplantio das mudas produzidas e tamanhos de células na bandeja. Horticultura Brasileira, v.23, n.3, p.837-840, 2005. Disponível em: <http://www.scielo.br/ scielo.php?script $=$ sci_arttext\&pid=S0102-05362005000300029>. Acessoem: 22 jan. 2012. doi:10.1590/S0102-05362005000300029.

KIEHL, E.J. Fertilizantes orgânicos: determinações analíticas. Piracicaba: Agronômica Ceres, 1985. 492p.

LIMA, C.J.G.S. et al. Avaliação de diferentes bandejas e substratos orgânicos na produção de mudas de tomate cereja. Ciência Agronômica, v.40, n.1, p.123-128, 2009. Disponível em: <http://www.ccarevista.ufc.br/seer/index.php/ccarevista/article/ view/413/309>. Acesso em: 29 jan. 2011.

MAKISHIMA, N. O cultivo das hortaliças. Brasília: EMBRAPA, 1993. 110p. (Coleção Plantar 4).

MALAVOLTA, E. ABC da adubação. 5.ed. São Paulo: Agronômica Ceres, 1989. 292p. MALAVOLTA, E. Manual de nutrição de plantas. São Paulo: Agronômica Ceres, 2006. 638p.

MENEZES JUNIOR O.G.; FERNANDES H.S. Vermicomposto na produção de mudas de Couve-flor. Agrociência, v.4, n.3, p.191-196, 1998. Disponível em: <http://www.ufpel.tche.br/faem/ agrociencia/v4n3/artigo10.pdf>. Acesso em: 29 jan. 2011.

MENEZES JÚNIOR, F.O.G. et al. Caracterização de diferentes substratos e seu desempenho na produção de mudas de alface em ambiente protegido. Horticultura Brasileira, v.18, n.3, p.164-170, 2000. Disponívelem: $<$ http://www.scielo.br/scielo.php?script=sci_ arttext\&pid=S0102-05362000000300004>. Acesso em: 29 jan. 2011. doi: 10.1590/S0102-05362000000300004. 
PERUCH, L.A.M. et al. Levantamento da intensidade da alternariose e podridão negra em cultivos orgânicos de brássicas em Pernambuco e Santa Catarina. Horticultura Brasileira, v.24, n.4. p.464-469, 2006. Disponível em: <http://www.scielo. br/scielo.php?pid=S0102-05362006000400014\&script $=$ sci arttext>. Acesso em: 29 jan. 2011. doi: 10.1590/S010205362006000400014.

REGHIN, M.Y. et al. Produtividade da chicória (Cichorium endivia L.) em função de tipos de bandejas e idade de transplante de mudas. Ciência e Agrotecnologia, v.31, n.3, p.739-747, 2007. Disponível em: <http://www.scielo.br/scielo.php?script=sci_ pdf\&pid=S1413-70542007000300021\&lng=pt\&nrm=iso\&tlng= pt>. Acesso em: 29 jan. 2011

RESENDE, M. et al. Pedologia: base para distinção de ambientes. Viçosa: Neput, 1997. 367p.

RESENDE, G.M. et al. Épocas de plantio e doses de zinco em alface tipo americana. Horticultura Brasileira, v.26, n.4, p.510-514, 2008. Disponível em: <http://www.scielo.br/scielo. php ?pid $=$ S0102-05362008000400017\&script $=$ sci_arttext $>$. Acessoem: 29 jan. 2011. doi. 10.1590/S0102-05362008000400017.
SCHMITZ, J.A.K. et al. Propriedades químicas e físicas de substratos de origem mineral e orgânica para o cultivo de mudas em recipientes. Ciência Rural, v.32, n.6, p.937-944, 2002. Disponível em: <http://www.scielo.br/scielo.php?script=sci_ pdf $\&$ pid $=$ S0103-84782002000600005\&lng=pt\&nrm=iso \&tlng $=$ pt>. Acesso em: 29 jan. 2011.

TAIZ, L. et al. Fisiologia vegetal. Porto Alegre: Artmed, 2004 $719 \mathrm{p}$.

TRANI P.E. et al. Produção de mudas de alface em bandejas e substratos comerciais. Horticultura Brasileira, v.22, n.2, p.290-294, 2004. Disponível em: <http://www.scielo.br/scielo. php?pid=S0102-\&script=sci_arttext $>$. Acesso em: 29 jan.2011. doi: 10.1590/S0102-05362004000200025.

VITTI, M.R. et al. Efeitos de substrato alternativo e comercial na produção de mudas de alface em ambiente protegido. Revista Brasileira de Agroecologia, v.2, n.1, p.1166-1169, 2007. Disponível:<http://www.abaagroecologia.org.br/ojs2/index.php/ rbagroecologia/article/view/6507/4812>. Acesso em: 29 jan. 2011. 